\title{
Perancangan Strategy Maps dan Balanced Scorecard pada PT Bahtera Abadi Gas Gresik
}

\author{
Irfan Aulia Hoesaini \\ Universitas Airlangga Surabaya \\ e-mail: irfan.aulia.sby@gmail.com
}

\begin{abstract}
The growth of the business of gas industry in Indonesia make firm that deals with this industry will develop. Increase in the number of a company that produces gas trigger intense competition to gain customers that there is to consume gas. PT Bahtera Abadi Gas is one of the company that moves in the field of gas industry national scale. On the way various customers than any other company have been handled by PT BAG that majority exists in the region of east java. An intense competition in gain customers of the company between a gas that with each other to cause to compete with companies in providing a bargain price that low and improved service quality to win over the competition. With a bargain price that is very competitive, companies should do the efficiency and effectiveness of its production in the process so as to achieve the level of its optimum profit. In order to continue to compete, required managerial instrument that can help to formulate a strategy company in accordance with the vision, mission and objectives of the company that can be translated into the act of operational in clear and measurable accomplishment. In addition a strategy company in the level of implementation can be functioned as instrument of the measurement of performance management in addition to the goal is to investigate the effectiveness of the application of the strategy itself, also to control the performance management and minimize the potential there is the deception. The result of research shows that PT BAG having strategic objectives in map competition that is reflected in four perspective balanced scorecard. Strategic objectives financial perspective is utilization assets, cost efficiency, increase revenue. The purpose of from the perspective of a customer is customer satisfaction, customer retention, customer acquisition. The purpose of internal from the perspective of a business process is of quality, delivery, healthy and safety work, develop sustainable relationship with supplier. From the perspective of the purpose of learning and growth is increase employee competency, increase productivity employee, recruit quality employee, improved teamwork, employee feedback systems, availability of information technology.
\end{abstract}

Keywords: vision, mission, strategy map, balanced scorecard

\section{PENDAHULUAN}

Indonesia memiliki kekayaan sumber daya energi. Beberapa sumber daya energi yang besar adalah minyak dan gas bumi yang vital dan strategis. Dalam program pembangunan nasional, minyak dan gas bumi memiliki peranan yang sangat penting sebagai sumber devisa dan bahan baku industri nasional. Sesuai dengan pasal 33 Undang-Undang Dasar 1945 bahwa minyak dan gas bumi merupakan sumber daya yang strategis, tidak terbaharukan yang dikuasai oleh negara serta komoditas vital yang menguasai hajat hidup orang banyak dan mempunyai peranan penting dalam perekonomian nasional sehingga pengelolaannya harus dapat maksimal memberikan kemakmuran dan kesejahteraan rakyat.

Untuk jangka panjang, permintaan akan energi cenderung akan meningkat di mana 90\% dari peningkatan permintaan tersebut akan berasal dari kawasan negara berkembang dengan China, India, dan Timur Tengah sebagai penggerak. Khusus untuk gas alam, dalam jangka panjang permintaan diperkirakan akan meningkat secara global hingga tahun 2020. Mengingat 
perkembangan ekonomi dan teknologi yang akan mendorong banyak pembangkit listrik berbasis BBM (bahan bakar minyak) dan batu bara untuk beralih memakai gas alam yang dipandang lebih ramah lingkungan. Hal tersebut juga harus didukung usaha pemerintah, BUMN maupun perusahaan yang bergerak di sektor migas agar dapat mengelola gas secara optimal dan mampu memenuhi kebutuhan masyarakat luas.

PT Bahtera Abadi Gas adalah perusahaan yang bergerak dalam sektor tengah yang melibatkan transportasi, penyimpanan, dan pemasaran gas (midstream) dan sektor hilir yang melibatkan pemrosesan dan pengolahan gas (downstream) industri gas Indonesia. Perusahaan ini baru berjalan selama tiga tahun. Sesuai dengan tujuan di tahun awal berdiri, PT Bahtera Abadi Gas berusaha menjadi perusahaan gas nasional berkelas dunia. Tentunya hal ini haruslah diseimbangkan dengan usaha-usaha signifikan yang dapat mendorong pertumbuhan perusahaan agar dapat mencapai targetnya. Pengukuran kinerja merupakan salah satu faktor yang sangat penting bagi organisasi. Di dalam sistem pengendalian manajemen, pengukuran kinerja merupakan usaha yang dilakukan pihak manajemen untuk mengevaluasi hasil-hasil kegiatan yang telah dilaksanakan oleh masing-masing bidang (Rumintjap, 2013).

Menjadi perusahaan yang berkembang membuat PT Bahtera Abadi Gas harus membenahi diri. Pembenahan secara internal ini dilakukan supaya perusahaan bisa terus eksis di bisnis minyak dan gas. Contoh pembenahan yang telah dilakukan misalnya dengan penyusunan struktur organisasi dan pembuatan SOP (standard operating procedures) untuk masingmasing bagian. Selain itu, dalam menghadapi persaingan, PT Bahtera Abadi Gas juga tidak bisa mengabaikan desakan dari faktor eksternal.
Inflasi dan fluktuasi suku bunga, perubahan peraturan perpajakan, terjadinya krisis global menjadi faktor-faktor eksternal yang memaksa banyak perusahaan minyak dan gas untuk melakukan penyesuaian dalam kondisi internalnya.

PT Bahtera Abadi Gas telah bersikap proaktif dalam menghadapi perubahan-perubahan yang terjadi. Visi dan misi sebenarnya sudah ada secara implisit, hanya saja penyesuaian yang dilakukan belum pernah dievaluasi keselarasannya terhadap strategi perusahaan. Adanya balance scorecard akan membuat visi, misi, dan strategi perusahaan tersampaikan secara eksplisit yang selanjutnya akan menjadi fondasi bagi sistem manajemen perusahaan. Untuk menjaga agar tindakan-tindakan yang dilakukan tetap berada dalam koridor yang benar (sesuai visi, misi, dan strategi perusahaan) maka balanced scorecard dipandang sebagai alat manajerial yang dibutuhkan oleh PT Bahtera Abadi Gas.

Penyusunan strategy maps dan balanced scorecard ke depannya sekaligus dapat berfungsi sebagai sistem kontrol dan pengendalian, karena di dalamnya juga tercakup pengukuran-pengukuran yang akan dipakai sebagai dasar penilaian performa. Serangkaian pengukuran yang dipilih merupakan key informance indicators (KPI) atas aspek-aspek tangible dan intangible yang sifatnya penting dalam perusahaan. Dengan fungsi sebagai pembelajaran dan pengendalian, balanced scorecard menjadi sistem manajerial yang tidak hanya berfokus pada masa sekarang, tetapi juga lebih mempertimbangkan kondisi jangka panjang perusahaan. Sehubungan dengan hal tersebut, Bahtera Abadi Gas membutuhkan rancangan strategy maps dan balanced scorecard untuk membantu setiap orang di perusahaan agar lebih mudah memahami alur strategi dan membantu mengukur keefektifan strategi yang diterapkan Bahtera Abadi Gas. Hal itu diharapkan agar 
Bahtera Abadi Gas dapat mencapai tujuan dan kesuksesan jangka panjang. Oleh karena itu, judul penelitian adalah Perancangan Strategy Maps dan Balanced Scorecard pada PT Babtera Abadi Gas Gresik.

\section{PERUMUSAN MASALAH}

Berdasarkan uraian pada latar belakang maka disusun rumusan masalah penelitian sebagai berikut: "Bagaimana Rancangan Strategy Maps dan Balance Scorecard pada PT Bahtera Abadi Gas?”

\section{TINJAUAN PUSTAKA}

\section{Balanced Scorecard}

Balanced Scorecard lebih dari sistem pengukuran operasional yang taktis. Perusahaan yang inovatif menggunakan scorecard sebagai sistem manajemen strategis yang menjadi pedoman dan tolak ukur pencapaian suatu target bagi perusahaan dalam kinerja sehari-hari, dan untuk mengatur strategi mereka dalam jangka waktu yang panjang. Menurut Kaplan dan Norton (1996), perusahaan menggunakan fokus pengukuran atau kerangka dari scorecard untuk menyelesaikan proses manajemen yang kritis sebagai berikut.

a. Memperjelas dan menerjemahkan visi, misi, dan strategi.

b. Mengomunikasikan dan menghubungkan objektif dari strategi dan pengukuran.

c. Perencanaan, penyusunan target-target, dan menyelaraskan inisiatif dari strategi.

d. Meningkatkan feedback dan learning strategi. Menurut Kaplan dan Norton (1996), balanced scorecard digunakan oleh perusahaan untuk hal-hal sebagai berikut.

a. Memperjelas dan mendapatkan kesepakatan mengenai strategi perusahaan. b. Mengomunikasikan strategi ke seluruh organisasi.

c. Menyelaraskan tujuan yang bersifat departemental dan personal pada strategi.

d. Menghubungkan tujuan-tujuan strategi pada target-target jangka panjang dan anggaran tahunan.

e. Mengidentifikasi dan menyelaraskan inisiatif strategis.

f. Mendapatkan feedback untuk belajar tentang dan mengembangkan strategi.

\section{Financial Perspective}

BSC memakai tolak ukur kinerja keuangan seperti laba bersih dan ROI, karena tolak ukur tersebut secara umum digunakan dalam perusahaan untuk mengetahui laba. Tolak ukur keuangan saja tidak dapat menggambarkan penyebab yang menjadikan perubahan kekayaan yang diciptakan perusahaan atau organisasi (Mulyadi dan Johny Setyawan, 2000). Balanced scorecard adalah suatu metode pengukuran kinerja yang di dalamnya ada keseimbangan antara keuangan dan non-keuangan untuk mengarahkan kinerja perusahaan terhadap keberhasilan. BSC dapat menjelaskan lebih lanjut tentang pencapaian visi yang berperan di dalam mewujudkan pertambahan kekayaan tersebut (Mulyadi dan Johny Setyawan, 2000) sebagai berikut.

a. Peningkatan customer yang puas sehingga meningkatkan laba (melalui peningkatan revenue).

b. Peningkatan produktivitas dan komitmen karyawan sehingga meningkatkan laba (melalui peningkatan cost effectiveness).

c. Peningkatan kemampuan perusahaan untuk menghasilkan financial returns dengan mengurangi modal yang digunakan atau melakukan investasi dalam proyek yang menghasilkan return yang tinggi. 


\section{Customer Perspective}

Dalam perspektif pelanggan, perusahaan perlu terlebih dahulu menentukan segmen pasar dan pelanggan yang menjadi target bagi organisasi atau badan usaha. Selanjutnya, manajer harus menentukan alat ukur yang terbaik untuk mengukur kinerja dari tiap unit operasi dalam upaya mencapai target finansialnya. Selanjutnya, apabila suatu unit bisnis ingin mencapai kinerja keuangan yang superior dalam jangka panjang, mereka harus menciptakan dan menyajikan suatu produk baru/jasa yang bernilai lebih baik kepada pelanggan mereka (Kaplan dan Norton, 1996). Produk dikatakan bernilai apabila manfaat yang diterima produk lebih tinggi daripada biaya perolehan (bila kinerja produk semakin mendekati atau bahkan melebihi dari apa yang diharapkan dan dipersepsikan pelanggan). Perusahaan terbatas untuk memuaskan potential customer sehingga perlu melakukan segmentasi pasar untuk melayani dengan cara terbaik berdasarkan kemampuan dan sumber daya yang ada.

\section{Internal Business Process Perspective}

Perspektif proses bisnis internal menampilkan proses kritis yang memungkinkan unit bisnis untuk memberi value proposition yang mampu menarik dan mempertahankan pelanggannya di segmen pasar yang diinginkan dan memuaskan harapan para pemegang saham melalui financial returns (Simon, 1999). Tiap-tiap perusahaan mempunyai seperangkat proses penciptaan nilai yang unik bagi pelanggannya. Secara umum, Kaplan dan Norton (1996) membaginya dalam tiga prinsip dasar.

a. Proses inovasi

Proses inovasi adalah bagian terpenting dalam keseluruhan proses produksi, tetapi ada juga perusahaan yang menempatkan inovasi di luar proses produksi. Di dalam proses inovasi itu sendiri terdiri dari dua komponen yaitu identifikasi keinginan pelanggan dan melakukan proses perancangan produk yang sesuai dengan keinginan pelanggan. Bila hasil inovasi dari perusahaan tidak sesuai dengan keinginan pelanggan maka produk tidak akan mendapat tanggapan positif dari pelanggan, sehingga tidak memberi tambahan pendapatan bagi perusahaan bahkan perusahaan harus mengelurkan biaya investasi pada proses penelitian dan pengembangan.

b. Proses operasi

Proses operasi adalah aktivitas yang dilakukan perusahaan, mulai dari saat penerimaan order dari pelanggan sampai produk dikirim ke pelanggan. Proses operasi menekankan kepada penyampaian produk kepada pelanggan secara efisien dan tepat waktu. Proses ini berdasarkan fakta menjadi fokus utama dari sistem pengukuran kinerja sebagian besar organisasi.

c. Pelayanan purna-jual Adapun pelayanan purna-jual yang dimaksud di sini, dapat berupa garansi, penggantian untuk produk yang rusak, dan lain-lain.

\section{Learning and Growth Perspective}

Sudut pandang keempat dari balanced scorecard yaitu learning \& growth, sudut pandang ini mengenal infrastruktur yang perusahaan harus bangun untuk menciptakan perkembangan dan pertumbuhan dalam jangka panjang. Pada sudut pandang ini perusahaan harus secara terus-menerus mengembangkan kemampuan untuk mengirimkan value, dengan kata lain introspeksi, perbaikan, dan pembelajaran agar perusahaan dapat terus bersaing pada persaingan global. Learning o growth organisasi/perusahaan datang dari tiga 
sumber, yaitu sumber daya manusia, Sumber daya informasi, dan budaya organisasi. Ketiga sumber ini pada balanced scorecard akan memiliki tujuan masing-masing. Sudut pandang learning \& growth menjadi fondasi bagi perusahaan untuk mendukung financial perspective, customer perspective, dan internal business process perspective. Secara bersama, balanced scorecard akan menerjemahkan visi dan strategi pada tujuan dan ukuran ke seluruh sudut pandang dari balanced scorecard. Keempat sudut pandang dari balanced scorecard tersebut akan berhubungan satu dengan lainnya pada hubungan sebab dan akibat yang terkait satu sama lainnya dan tidak berdiri sendiri.

\section{Visi, Misi, dan Strategi}

Ada tiga pertanyaan yang harus dijawab perusahaan dalam beraktivitas sehari harinya, Menurut Gamble dan Thompson (2009), yaitu di mana saat ini perusahaan berada? Ke mana tujuan yang ingin dicapai? dan bagaimana cara untuk pergi ke tujuan tersebut?, Ketiga pertanyaan inilah menjadi dasar dalam bagaimana memahami visi, misi, dan strategi yang telah ditetapkan semenjak awal dibentuknya perusahaan tersebut. "Bagaimana cara untuk mencapai tujuan tersebut?" suatu pertanyaan yang sesuai dengan istilah Strategi. Strategi terdiri dari gerakan-gerakan dan pendekatan-pendekatan bisnis yang dikembangkan oleh manajemen untuk menarik dan menyenangkan pelanggan, melakukan operasi, menumbuhkan bisnis, dan mencapai tujuan dari kinerja. Ada banyak macam strategi dari perusahaan yang diterapkan pada saat ini, contohnya: cost-based advantage strategy, differentiation based advantage strategy, narrow niche market strategy, dan banyak strategi lainnya.

\section{Strategy Map}

Menurut Kaplan dan Norton (2004), saat ini aset berbasis pada knowledge semakin berkembang dan digunakan di seluruh industri dan bisnis. Ditambah pula dengan perkembangan dari pendekatan sistem manajemen strategis balanced scorecard. Pada saat ini tanggapan positif dari top manajemen sangat baik pada pendekatan sistem manajemen terbaru tersebut. Tetapi para top manajemen ingin menggunakan sistem terbaru tersebut supaya bisa diaplikasikan lebih kuat dari apa yang sebelumnya, dan mereka menginginkan agar sistem tersebut dapat memecahkan masalah lebih penting yang mereka hadapi yaitu bagaimana untuk mengimplementasikan strategi yang baru. Jadi top manajemen di seluruh dunia pada saat ini menghadapi dua tantangan yaitu bagaimana untuk menggerakkan sumber daya human capital dan information, dan bagaimana untuk mengubah organisasi mereka ke strategi terbaru, didorong oleh pelanggan yang terinformasi dan cerdas yang menginginkan kinerja perusahaan yang sangat baik.

\section{KERANGKA KONSEP PENELITIAN}

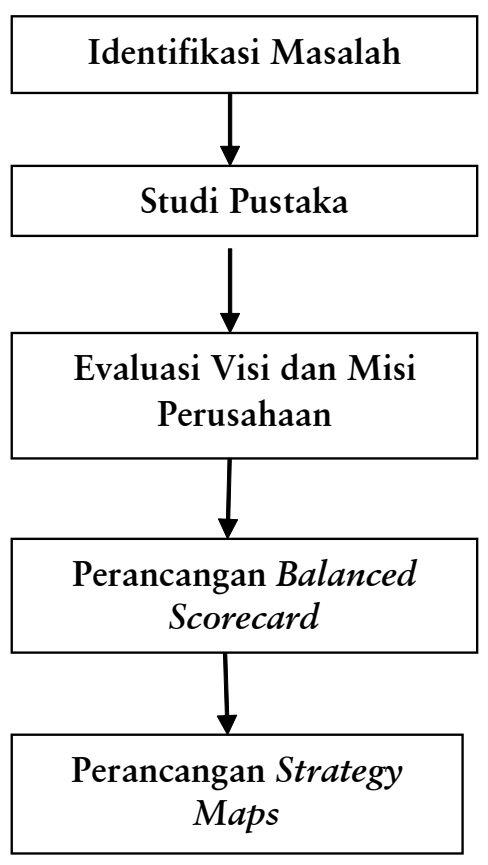




\section{METODE PENELITIAN}

Pendekatan penelitian yang digunakan dalam penelitian ini adalah penelitian kualitatif. Secara spesifik penelitian ini adalah penelitian yang bersifat eksploratoris. Penelitian eksploratoris yang digunakan dalam penelitian ini dilakukan dengan studi mendalam serta mempertimbangkan kedalaman data. Dengan kata lain bahwa penelitian eksploratoris ini bertujuan untuk mengeksplor dan memudahkan untuk mendeskripsikan objek dan subjek penelitian secara sistematis, faktual, dan akurat dalam mengidentifikasi visi, misi, dan strategi perusahaan yang masih bersifat implisit.

\section{Lokasi Penelitian dan Unit Analisis}

Lokasi penelitian ini dilakukan di PT Bahtera Abadi Gas yang bertempat di Tuban. Pemilihan tempat penelitian ini dengan pertimbangan mempermudah jangkauan informasi dan pengumpulan data saat melakukan wawancara. Unit analisis yang akan digunakan sebagai objek penelitian adalah penyusunan strategy maps dan balanced scorecard.

\section{Jenis dan Sumber Data}

Jenis penelitian ini adalah eksploratoris yakni dengan melakukan peninjauan atau observasi keadaan internal dan eksternal PT Bahtera Abadi Gas. Kegiatan ini berguna untuk mendapatkan gambaran secara sistematis mengenai fakta pada objek penelitian sesuai dengan pokok permasalahan yang diteliti, kemudian membuat perbandingan dan analisis dengan teori yang digunakan.

\section{Kisi-Kisi Pertanyaan Penelitian}

\begin{tabular}{|l|l|}
\hline \multicolumn{1}{|c|}{ Responden } & \multicolumn{1}{c|}{ Pertanyaan Wawancara } \\
\hline Direktur & 1. Apa harapan Anda ketika awal mendirikan \\
& 2. $\begin{array}{l}\text { Segmen kepuasan yang mana yang dibidik oleh } \\
\text { PT Bahtera Abadi Gas? }\end{array}$ \\
& $\begin{array}{l}\text { 3. } \begin{array}{l}\text { Bagaimana dengan harga jual produk dan atau } \\
\text { jasa PT Bahtera Abadi Gas bila dibandingkan } \\
\text { dengan pesaingnya? }\end{array} \\
\text { 4. Strategic issue yang ada dalam perusahaan } \\
\text { terdiri dari apa saja? }\end{array}$ \\
\hline Internal & 5. Apa saja hal-hal penting yang menjadi faktor \\
deparses perusahaan?
\end{tabular}

\section{Teknik Analisis}

Sejalan dengan permasalahan dalam penelitian ini, kerangka konseptual sebagai gambaran proses penelitian yang akan dilakukan sesuai dengan langkah-langkah yang disusun oleh Rohm and Habach (2006).

\section{ANALISIS DAN PEMBAHASAN HASIL PENE- LITIAN}

\section{Analisis Visi dan Misi PT BAG}

Visi merupakan pernyataan yang berisi gambaran keadaan organisasi yang ingin dicapai di masa yang akan datang. Visi menjawab pertanyaan "kita ingin menjadi apa di masa depan?" Visi adalah tentang pandangan yang jauh, merupakan petunjuk atau arahan tentang apa yang harus dilakukan untuk mencapai tujuan. Menjadi perusahaan terkemuka sebagaimana disebutkan PT BAG dalam visinya mengandung arti bahwa PT BAG ingin menjadi yang paling unggul dan dikenal di antara para pelaku industri gas lain- 
nya. Peneliti menilai pernyataan visi PT BAG tersebut terlalu optimis dan berambisi, apabila ditinjau dari capaian perusahaan yang telah diraih masih butuh perbaikan dalam kinerja manajemennya. Adapun dari pernyataan visi PT BAG disebutkan kata komersial yang mengandung arti hanya berorientasi pada keuntungan saja dan tidak menjaga kualitas layanan dari PT BAG kepada pelanggannya. Akan tetapi, berdasarkan wawancara dengan Top Management kata

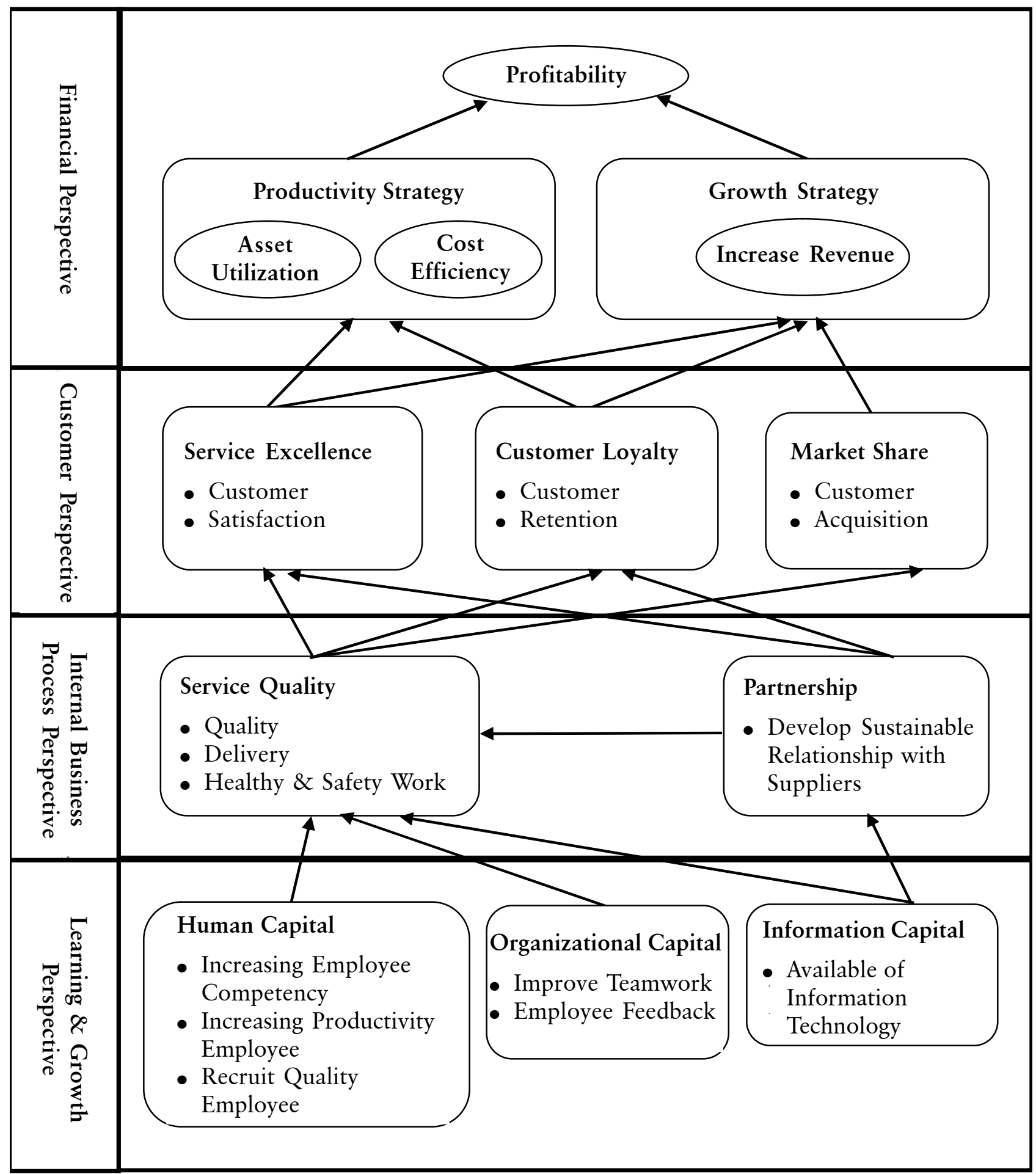


komersial tersebut sebenarnya merupakan pangsa pasar dari PT BAG yang mencakup hotel, mall, dan usaha lain non-Industri besar, hal ini terlihat bahwa adanya penggunaan kata yang bersifat ambigu. Di sisi lain, pada kenyataannya selama hampir tiga tahun sejak berdiri PT BAG hanya melayani pangsa pasar industri saja mulai dari industri besar, menengah, sampai kecil. Oleh karena itu, peneliti dalam hal ini menyarankan agar visi yang tertulis lebih spesifik kepada pangsa pasar industri saja.

\section{Analisis Tujuan Perusahaan}

Tujuan PT BAG tersebut menitikberatkan pada tercapainya kepuasan pelanggan yang dihasilkan melalui akurasi proses produksi tertinggi sehingga proyeksi keuntungan dapat tercapai secara optimal. Dapat kita cermati bahwa tujuan PT BAG menggambarkan adanya hubungan sebab akibat antara perspektif bisnis internal yaitu proses produksi yang menghasilkan kepuasan pelanggan dan selanjutnya akan mengarah pada tercapainya sasaran perspektif finansial. Secara eksplisit tujuan tersebut menggambarkan suatu pola bagaimana tujuan tertinggi perusahaan yaitu dari segi finansial dapat tercapai.

\section{Analisis Strategi PT BAG}

Dalam rangka memenangkan persaingan dan meningkatkan keuntungan perusahaan, strategi yang dijalankan PT BAG dapat dikategorikan ke dalam strategi cost leadership (kepemimpinan biaya), salah satu konsep strategi persaingan yang sangat populer yang dikemukakan oleh salah seorang pakar ekonomi Michael E. Porter. Cost leadership adalah suatu strategi bersaing di mana perusahaan berhasil memproduksi barang atau jasa pada biaya yang paling rendah di dalam industrinya. Dengan biaya yang sangat efisien maka perusahaan dapat menetapkan harga penawaran yang kompetitif sehingga memiliki peluang lebih besar dalam memenangkan persaingan. Keunggulan biaya biasanya dihasilkan dari produktivitas proses produksi, distribusi, atau keseluruhan operasi perusahaan.

\section{SIMPULAN DAN SARAN}

\section{Simpulan}

Berdasarkan hasil analisis dan pembahasan penelitian mengenai "Penyusunan Strategy Map dan Balanced Scorecard pada PT Bahtera Abadi Gas" maka dapat diambil kesimpulan berdasarkan rumusan masalah penelitian sebagai berikut. 1. Strategi yang digunakan PT Bahtera Abadi Gas yaitu memberikan kualitas pelayanan terhadap pelanggan yang sesuai dengan kebutuhan dan keinginan pelanggan.

2. Berdasarkan visi, misi, dan strategi, disusunlah strategy map dan balanced scorecard pada PT Bahtera Abadi Gas dengan strategy objective (sasaran strategis) pada masingmasing perspektif sebagai berikut.

a. Pada perspektif keuangan sasaran strategisnya adalah asset utilization, cost efficiency, dan increase revenue.

b. Pada perspektif pelanggan sasaran strategisnya adalah customer satisfaction, customer retention dan customer acquisition.

c. Pada perspektif proses bisnis internal sasaran strategisnya adalah quality, delivery, healthy and safety work dan develop sustainable relationship with supplier.

d. Pada perspektif pembelajaran dan pertumbuhan sasaran strategisnya adalah increasing employee competency, increasing productivity employee, recruit quality employee, improve teamwork, employee feedback, availability of information technology. 
Saran

Berdasarkan hasil analisis dan pembahasan serta hasil wawancara, disarankan untuk segera mengomunikasikan visi, misi, dan strategi perusahaan serta mengimplementasikan rancangan strategy map dan balanced scorecard untuk meningkatkan kinerja dan mengadakan perbaikan secara internal untuk dapat mencapai tujuan perusahaan. PT BAG perlu membentuk tim yang bertugas untuk hal-hal sebagai berikut.

1. Memeriksa kembali visi, misi, dan strategi perusahaan yang ada.

2. Mereview strategy map dan balanced scorecard dalam penelitian ini untuk diimplementasikan.

3. Menetapkan inisiatif dan menyiapkan anggaran yang diperlukan untuk melaksanakan inisiatif yang sudah ditetapkan.

4. Mengevaluasi keberhasilan strategi bisnis yang dipilih dan merevisinya bila diperlukan, evaluasi sebaiknya dilakukan secara berkala setiap semester sekali.

\section{DAFTAR RUJUKAN}

David, Fred R. 1995. Strategic management, Six Edition. Prentice Hall.

Gamble, John E and Thompson, Arthur A. Jr. 2009. Essentials of Strategic Management: the Quest for Competitive Advantage, Second Edition. New York: McGraw-Hill.

Grant R.M. 2002. Contemporary Strategy Analysis, Fourth Edition. Oxford, UK: Blackwell Publishers.

Kaplan, R.S., dan Norton, D.P. 1996. Balanced Scorecard: Translating Strategy into Action. Boston: Harvard Business School Press.
Kaplan, R.S., dan Norton, D.P. 2004. Strategy Maps: Converting Intangible Assets into Tangible Outcomes. Boston: Harvard School Press.

Marzuki. 2002. Metodologi Riset. Yogyakarta: BPFE UII. Madcoms. 2002. Yogyakarta: Andi.

Moleong, Lexy J. 2002. Metodologi Penelitian Kualitatif. Bandung: Remaja Rosdakarya.

Mulyadi. 2001. Balanced Scorecard. Edisi ke-2. Jakarta: Penerbit Salemba Empat.

Mulyadi dan Johny Setyawan. 2001. Sistem Perencanaan \& Pengendalian Manajemen. Edisi ke-2. Cetakan ke-1, hlm. 424. Jakarta: Salemba Empat.

Pandey, I.M. 2005. Financial Management. Nine Edition. New Delhi: Vikas Publishing House PVT, Ltd.

Pearce, J.A. \& Robinson, R.B. 1998. Strategic Management: Strategy Formulation and Implementation, third edition. USA: Richard D. Irwin, Inc.

Rhom, Howard, Halbach, Larry. 2006. A Balancing Act: Sustaining New Direction. In: Perform, Volume 3, Issue 2, 2006, pp. 18.

Rumintjap, L. Marisa. 1993. Penerapan Balanced Scorecard sebagai Tolak Ukur Pengukuran Kinerja di RSUD Noongan. Jurnal EMBA. Fakultas Ekonomi dan Bisnis, Jurusan Akuntansi, Universitas Sam Ratulangi Manado.

Thompson, A.A. \& Stricklan, A.J. 2001. Strategic Management: Concept and Cases. 12 Edition. New York: McGraw-Hill Irwin.

Wheelen, L., Thomas \& Hunger, David. J. 2002. The Study of Strategic Management. In Strategic Management and Business Policy. Eight Edition. New Jersey: Prentice Hall. 
Wibisono, Dermawan. 2006. Manajemen Kinerja: Konsep, Desain, dan Tehnik Meningkatkan Daya Saing Perusahaan. Jakarta: Penerbit Erlangga.
Yin, Robert K. 2012. Studi Kasus-Desain \& Metode. Jakarta: PT Raja Grafindo Persada. 